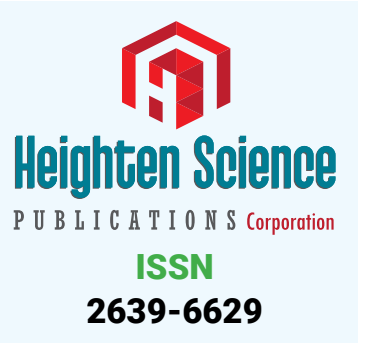

*Address for Correspondence: Dr. Roberto Carlos Burini, Nutritional and Exercise Metabolism Center, UNESP School of Medicine, São Paulo State University, Brazil, Email: burini@fmb.unesp.br

Submitted: 28 December 2017

Approved: 25 January 2018

Published: 26 January 2018

Copyright: @ 2018 Burini RC, et al. This is an open access article distributed under the Creative Commons Attribution License, which permits unrestricted use, distribution, and reproduction in any medium, provided the original work is properly cited.

Keywords: Blood hypertension; Primary care Epigenetics; Physical exercises
Research Article

\section{Treating Blood Hypertension in a Brazilian Community: Moving from Reactive Homeostatic Model to Proactive Allostatic Healthcare}

\author{
Roberto Carlos Burini ${ }^{1,2 *}$, Mariana Santoro Nakagaki ${ }^{1,3}$, \\ Edilaine Michelin ${ }^{1}$ and Franz Homero Paganini Burini ${ }^{1,4}$ \\ ${ }^{1}$ Nutritional and Exercise Metabolism Center, UNESP School of Medicine, São Paulo State \\ University, Brazil \\ ${ }^{2} \mathrm{PhD}$, Full Professor of Pathology, Dept. of Public Health, UNESP School of Medicine, Brazil \\ ${ }^{3}$ Graduate Student of Physical Education, Londrina State University (UEL), Physical Education \\ and Sport Center, Parana, Brazil \\ ${ }^{4}$ MD. PhD. Sports Medicine Physician of the UNESP Medical School-Clinical Hospital, Brazil
}

\section{Abstract}

The responsiveness of hypertensive subjects to different types of physical exercises and length of intervention, has been investigated in samples of our dynamic cohort study ("Move for Health" program) based on spontaneous demand for healthy lifestyle with supervised exercises and dietary counseling. After clinical selection and baseline assessments they were spontaneously assigned to exercise protocols of strength (PAc) isolated or combined with endurance (walking) exercises (PMi) daily or in alternated days $(\mathrm{PMiA})$, hydrogymnastics(PHy) and tread mill high- intensity exercises(PHit), applied during 10 (experiment 1 ) and 20(experiment 2) weeks of intervention. Baseline demographic, socioeconomic, anthropometric and physical activity and fitness characteristics were similar among protocols. Ten-week training improved V02max. Similarly in all protocols while hand grip increased only in PAc. In average, there was a $16 \%$ reduction rate of hypertension rate from baseline with both, SBP and DBP, reduced by PHy and only SBP by the PMi. After adjustments hypertension was more reduced by PAc, PMi and PHy. In the 20-week experiment, higher SBP was similarly reduced by PAC or PMiA and DBP by PMiA, after adjustments. Hence, so far, our generated data suggest physical exercises as an effective tool for hypertension reduction, from 10 weeks to 3 year-long supervised protocols composed by surface or aquatic activities with strength or endurance exercises. PAc takes longer and shortperiod responsiveness can be achieved by either combined (strength-endurance) or hydrogymnastic exercises. Thus, exercise training is a time-and type-dependent tool, feasible, costless and scientific-based rheostaticallostatic alternative for the current "sick-care" drug-dependent homeostatic approach to hypertension med care.

\section{Introduction}

High blood pressure (HBP) is a strong, independent and etiologically relevant risk factor for cardiovascular and therefore, the leading cause of preventable deaths worldwide [1]. Roughly one-quarter of US adults are hypertensive (blood pressure $>140 / 80 \mathrm{~mm} \mathrm{Hg}$ on repeated measurement) and 95\% are classified as "essential" hypertension [2]. Projections are that by the year of $2025,75.0 \%$ (or 1.17 billion people) of the people with hypertension in the world will be living in emerging nations [3]. It is estimated that about one-third of the population in Latin America is affected by Blood Hypertension. Baseline findings (2014) from ELSA-Brasil show a frequency of $35.8 \%$ high blood pressure [4]. Hypertension has high medical and social costs, primary due to its many associated complications which lead to more severe cardiovascular disease, mortality, morbidity, incapacity and the use of medical services worldwide, factors that create high costs [5]. The Brazilian Public Health System is free and universal that intends to provide health care free of charge to its 
whole population. Since 1990 it has been organized by the Unified Health System (SUS-Sistema Unico de Saude) and the Family Health Strategy (ESF) was introduced in 1994, aiming to reorganize primary health care through the implementation of multidisciplinary professional teams. The strategy aims to rationalize the use of all levels of assistance (primary, secondary and tertiary) [6]. The free distribution of medicines occurs since 1971. The distribution of more than 15 medications for HyPERtension and DIAbetes (HIPERDIA program, begun in 2001), and the governmental fueling pharmaceutical-care expansion, clearly shows the important role of drugs in the Brazilian Government's effort to tackle these two diseases [7,8]. In Brazil, the cost of medication spent with either one (US\$ 87.10), two (US\$159.00) or three (US\$ 194.00) drugs averaged US\$39.50/month for each diagnosed hypertensive subject [9]. The estimated direct cost of hypertension treatment in this country is 1.46 times higher in public than the private system. Together they represented $0.08 \%$ of the GDP (in 2005), or $1.11 \%$ of overall health care costs [10]. Data sources on HiperDia Program are controlled mostly by the Ministry of Health and the available data are fragmentary and often outdated [8]. When looking at the effectiveness scale it is unquestionable that prevalence of diabetes and hypertension are still rising [11]. From 2006 to 2010, according to VIGITEL, the self-reported prevalence of diabetes increased $5.3 \%$ in 2006 to $6.3 \%$ in 2010, leading to an approximate $20 \%$ increase [7]. Hypertension is estimated to present a $60 \%$ increase by the year 2025 . Projections are that by the year of $2025,75.0 \%$ (or 1.17 billion people) of the people with hypertension in the world will be living in emerging nations [12]. Thus seems that besides onerous, the SUS care of HyPERtension and DIAbetes has been demonstrated as ineffective. It is known that therapy is the attempted remediation of a health problem following a diagnosis. In the case of hypertension seems that is having a lacking of both, lack of real aknowledge of the health problem (disease) and/or misinterpretation of the blood pressure variation, by the caregiver professional.

\section{Knowing epigenetics of blood pressure variation}

Elevated blood pressure results from environmental factors, genetic factors, and interactions among these factors [13]. Our ancestors were often faced with survival stresses, including famine, infection and water and sodium deprivation. As results of natural selection, the survival pressures drove our evolution to shape a thrifty genotype, which favored/ promoted energy-saving and sodium/water preservation. However, with the switch to a sodium- and energy-rich diets and sedentary lifestyle, the thrifty genotype and ancient frugal alleles, are no longer advantageous, and may be maladaptive to disease phenotype, resulting in hypertension, obesity and insulin resistance syndrome [1,14-16]. Particularly on the blood pressure control, our ancestors were faced with the hot and humid climate, like in eastern Africa. Effective heat dissipation is essential in hot environments and is achieved most efficiently through evaporative heat loss [17]. However, sweating due to the hot climate and excessive labor activities can lead to a large loss in the amount of salt and water, and eventually lead to hypovolemia, a threat to human survival. In addition, human and nonhuman primates living in ancient times had very low salt intake available. Low salt intake and large salt losses due to sweating had created robust salt appetite and renal sodium conservation, which were essential to survival [18]. Water loss and sodium deprivation due to insufficient sodium intake or excess sodium loss may activate renninangiotensin-aldosterone system, sympathetic nerve or neuroendocrine system to preserve sodium. The accumulation of sodium in tissue is accompanied by a commensurate retention of water to maintain the isotonicity of body fluids [18]. And, consequently, maintaining blood pressure [19]. Moreover, by facing infection, trauma and physical stress [20], there was an activation of the innate and adaptive immune system and, the acute inflammatory episode may cause water loss. Hence, to cope with the injury responses, a coordination of neuroendocrine, energy storage, water economy and immune systems are adapted. Some hormones that mediate water retention such as angiotensin II and aldosterone are also endowed with pro-inflammatory effects, and has an important 
role in the pathogenesis of hypertensive and metabolic diseases. Moreover, immune cells, such as mononuclear phagocyte system and macrophages, are responsible for interstitial hypertonic sodium retention, resulting from high salt diet intake, and stimulate lymphcapillary network formation. Notably, neoformed vessels (angiogenesis) in skin may serve as an extra sodium and water storage to buffer extra-cellular volume expansion and maintenance of blood pressure homeostasis. Hence, immune system plays some role in the regulation of sodium and water homeostasis [21]. Additionally, inflammatory cytokines released from activated immune cells inhibits insulin signaling pathway. In addition to its metabolic effects, insulin induces vaso- relaxation and regulates sodium homeostasis by enhancing sodium reabsorption in the kidney, thereby, contributing to the regulation of blood pressure [18,22]. Thus, the increased blood pressure by insulin resistance may contribute to increased blood perfusion to the brain during starvation and infection, and to the fetus during pregnancy [23]. Therefore, negative regulation of insulin signaling could be viewed as a physiologic 'adaptive mechanism" that is activated in certain conditions such as fasting, inflammation, stress and pregnancy $[18,22]$. Because organisms adapt to the totality of their environment, or ecological niche, it is hypothetically possible that natural selection favors organisms harboring the genotype for a metabolic system [18]. Thereby, as results of natural selection, the survival pressures drove our evolution to shape a thrifty genotype, which favored/promoted energy-saving and sodium/water preservation [24]. Though, at least two genes: angiotensinogen (AGT) and the epithelial sodium channel $\gamma$ subunit $(\mathrm{ENaC} \gamma)$, are involved in the regulation of sodium and blood pressure homeostasis [25]. However, this natural selection of thrifty genotype, which was a physiological adaptive mechanism for human survival, on the current environment, is maladaptive to disease phenotype $[18,20,23,26]$. As such, salt- sensitive hypertension sodium-conserving (thrifty) genotype may be maladaptive to the modern environment of sodium abundance [24]. Thus, epigenetic high blood pressure results from the mismatch of our ancestral thrifty genotype which favored/promoted energy-saving and sodium/water preservation, with a contemporary sodium- and energy-rich diets and sedentary lifestyle environment [14].

\section{Knowing the target of treatment}

Man and animals are exposed to a large number of biological and environmental factors (stressors) like alterations in feed and husbandry practices, climatic variables, transportation, regrouping, the therapeutic and prophylactic activities etc. The ability of the man and animal to fight against these factors is important for maintenance of their health and productivity [27]. The presence of a stressor leads to the activation of neurohormonal regulatory mechanisms of the body, through which it maintains the homeostasis [28]. Homeostasis is the property of a system within the body in which a variable is actively regulated to remain very nearly constant. Though, homeostasis is the regulation of the body to a balance, by single point tuning. The homeostatic regulation occurs despite changes in the animal's environment, or what it has eaten, or what it is doing (for example, resting or exercising). Each of these variables is controlled by a separate "homeostat" (or regulator), which, together, maintain life. Homeostats are energy-consuming physiological mechanisms. On the other hand, allostasis is the process of achieving stability through physiological or behavioral change. The concept of allostasis, maintaining stability through change, is a fundamental process through which organisms actively adjust to both predictable and unpredictable events [29]. This can be carried out by means of alteration in HPA axis hormones, the autonomic nervous system, cytokines, or a number of other systems, and is generally adaptive in the short term [30]. Both homeostasis and allostasis are endogenous systems responsible for maintaining the internal stability of an organism [27] as well, both respond to stressors motivated by stress. Stress can be defined as a process of altered biochemical homeostasis produced by psychological, physiological, or environmental stressors [28]. On the basis of duration and onset, stress might be acute and chronic and generally released with the removal of cause. 
Homeostasis describes mechanisms that hold constant a controlled variable by sensing its deviation from a "setpoint" and feeding back to correct the error. Consequently physicians design therapies to restore the "inappropriate" value to "normal". However, in medicine, major diseases now rise in prevalence, such as essential hypertension and type 2 diabetes, whose causes the homeostasis model cannot explain [31]. Pressure spends about equal time above and below the steady daytime level. This pattern suggests, not defense of a setpoint, but rather responsiveness to rising and falling demand. Once the brain predicts the most likely demand, it resets the blood pressure to match. To do so, the brain directly modulates all three primary effectors: nerves signal the heart to pump faster, blood vessels to constrict, and kidneys to retain salt and water. These direct neural messages are reinforced by additional signals acting in parallel. For example, the neural system that excites the primary effectors also releases multiple hormones that send them same message. Hormones signaling the opposite message are suppressed. This pattern: multiple, mutually reinforcing signals acting on multiple, mutually reinforcing effectors, overrides the various feedbacks that oppose change. Recognizing such fluctuation, it has been proposed the idea of shifting setpoints termed, "rheostasis". Essentially all biological parameters fluctuate with different amplitudes and time constants, and these fluctuations all share a single goal. Yet the goal is not constancy, but coordinated variation to optimize performance at the least cost. This is the core idea of allostasis [31].

\section{The allostasis approach to hypertension}

The homeostasis model cannot explain essential hypertension because it attributes all pathology to a "defect"-to something "broken". But the allostasis model suggests that there is no defect. More parsimoniously, it proposes that hypertension emerges as the concerted response of multiple neural effectors to prediction of a need for vigilance. When this prediction is sustained, all the effectors, both somatic and neural, adapt progressively to life at high pressure [31]. The neural signals that call for increased blood pressure also call for salty foods-which the fast-food industry ("industrial agriculture") provides in prodigious quantity. Industrial agriculture does not cause hypertension by excessively salting prepared foods; it merely obliges the public's appetite for sodium, which is driven quite appropriately by intact regulatory systems. Indeed, if under present conditions of life, the food industry were to restrict sodium, we might see the development of public "salt licks" [31]. Vigilance starts when a child is delivered from its mother's protection to the care of strangers. In a younger person if the predicted need for vigilance declines, effector adaptations can reverse promptly. But persistent demand leads to more profound and persistent effector adaptations. Over decades the constant call for vigilance adapts arterial muscle and carotid sinus to thicken and stiffen so that pressure rarely returns to normal levels [31].

Probably there are also corresponding adaptations in the brain. We know now that adult synapses continuously adjust their molecular components and that "memories" are stored at all levels, even in the spinal cord [32-33]. So the many hormones that feed back to the brain to sustain high pressure probably entrain many levels to expect and support high pressure. Thus, coordinated somatic and brain adaptations generate response patterns of "established" hypertension. The hypertensive pattern, like the normal pattern, does not seem to be "defended" at a particular level. Rather it is modulated up and down, apparently according to demand, with an overall range of 140 points. This pattern suggests adaptation to chronic vigilance, and consistent with this the hypertensive pattern is absent in undisrupted preindustrial societies where children remain in contact with their parents and strangers are rare [34]. Established hypertension is most common in segments of modern society where family structure is most disrupted, where children are least protected, and where they are marked from birth for suspicion and various forms of ill-treatment. So to explain essential hypertension there is no need to postulate a "defect" in any particular regulatory pathway. Certainly hypertension state might be created by mutation of one gene or another (Wilson et al., 2001). But we can also create hypertension and atherosclerosis in a whole colony of mice simply by introducing a stranger [35]. 
Certainly we recognize that the variance of blood pressure within a community must be partially caused by genetic differences. But this cannot explain why blood pressures of essentially all our children rise with age. Nor why the rise is largest and most persistent in the poorest and most socially disrupted communities. Nor why African-Americans are more hypertensive than genetically similar populations in West Africa. These observations certainly point to an environmental cause [31]. In summary, the allostasis model attributes the pathogenesis of hypertension to prolonged adaptation to hypervigilance and hyposatisfaction. The impact is strongest among populations with the best reasons for vigilance, the narrowest range of satisfactions, and expectations that are least often met [31].

\section{Knowing the rational therapeutics}

For responsiveness to rising and falling demand of blood the brain predicts the most likely demand, and resets the blood pressure to match. To do so, the brain directly modulates all three primary effectors: nerves signal the heart to pump faster, blood vessels to constrict, and kidneys to retain salt and water. Once diagnosed the hypertension, and following the homeostasis model, physicians try to restore each parameter to what they consider an "appropriate" level. Therefore, hypertension is treated with drugs that target the three primary effectors of elevated pressure: (i) diuretics to reduce blood volume; (ii) vasoconstrictor antagonists to dilate the vascular tree; (iii) heart rate antagonists to reduce cardiac output (Sterling, 2004). For so, the pharmaceutical industry continues to target myriad molecules that regulate these three mechanisms, and fundamental research widely promises to identify new targets. However, there are three problems with targeting low-level mechanisms. First, each signal evokes multiply cascaded effects, so even the most specific molecular antagonist will cause a cascade of effects. For example, in hypertension the angiotensin converting enzyme affects all of angiotensin's myriad downstream targets (arteriolar muscle, kidney, and multiple brain sites), and so also does its widely prescribed inhibitor [31].

Second, the variables targeted for treatment are being driven to their particular levels by concerted signals from the brain in response to predicted needs. Consequently, if one signal is suppressed by a drug, the brain compensates by driving all the others harder. Thus, when blood pressure is treated by a diuretic to reduce volume, there are compensatory increases in heart rate and vasoconstriction. These can be treated in turn by beta- adrenergic antagonists, calcium channel antagonists, etc. [34,36].

Third, there is a cost to performance in clamping a variable to some target level by blocking the effectors designed to modulate it. Clamping renders that variable insensitive to predicted need, which oposes the whole point of physiological regulation. Thus clamping blood pressure low with a beta-blocker commonly causes "exercise intolerance"-inability to increase cardiac output when it is needed [31].

A more rational goal of intervention would be to shift the predicted distribution of demand back toward its original level. This would allow the effectors to naturally reestablish flexible variation around the predicted lower demand, thus preserving the range of responsiveness. In other words, by rational therapy, when demand is reduced for long periods, the system re-adapts to the initial demand distribution. The mean response returns to its initial level while responsiveness is maintained [31].

This seems to work very much for hypertension while considering that the current authoritative recommendations for treatment are no longer drugs but: (i) weight loss; (ii) exercise; (iii) moderate alcohol consumption; (iv) diet reduced in sodium and fat and increased in calcium, potassium, and fiber; (v) cease smoking [36]. Particularly under the "DASH" study, it was found overall reductions in blood pressure "comparable to or greater than those usually seen with monotherapy (i.e., 1 drug) for stage 1 hypertension". But as the DASH study notes, long-term health benefits "will 
depend on the ability of people to make long-lasting dietary changes, including the consistent choice of lower- sodium foods" and "upon (their) increased availability" [37]. This requires, in effect, a sustained victory in the prefrontal cortex of abstract knowledge about what is "good for you" over all the unsatisfied appetites that cause the problem in the first place. The most successful interventions do not deny the sense of need. Rather, they find ways to satisfy it by enlarging positive social interactions and revivifying the sense of connectedness [31].

\section{Purpose}

Drug therapy has been largely unsuccessful in halting and reversing the hypertension epidemic and the epigenetics studies point out the prevalence of hypertension as perpetrated by lifestyle factors, such as poor dietary habits, physical inactivity, cigarette smoking/secondhand smoke and strongly associated with various sources of social distress. The plethora of used drugs that essentially attempt to substitute for a healthy lifestyle has resulted in failure and prohibitive cost. In the implementation of effective population-based strategies, diet and physical exercise are the pillars of treatment. In previous experiments we had shown aerobic supervised exercises of walking-jogging leading to hypertension decreasing in a 3-year follow up. SBP normalized earlier (4 mo.) than DBP (6 mo.), with $31.6 \%$ of the patients normalizing both at $8 \mathrm{mo}$. Intervention [5]. Later on, in the same community but under 10-weeks of a mixed exercise protocol, there was a $8.5 \%$ decreasing in SBP hypertension and in 5.2\% DBP [14]. Presently, we intend to add further informations regarding the hypertension responsiveness to protocols with different types of exercises interacting with short (10 weeks) and long (24 weeks) period of intervention.

\section{Material and Methods}

\section{Subjects}

Participants of were enrolled at the "Move for Health Program"(Programa Mexa-se Pró-Saúde), an ongoing epidemiology project conducted, as extension-assistance of the university, since 1991. The program introduces healthy lifestyle into subject's diary activities by promoting nutritional re-education and supervised physical exercise as primary care for chronic non-communicable diseases. As a community -based project it includes adult ( $>35$ yrs old) participants from both genders that come to the clinic spontaneously or by either a friend or doctor indication looking for preventive health examination with further non-medicated interventions. Upon registration and accomplishing ethical requirements the subjects are submitted to multi professional assessments for clinical, anthropometric, dietary, physical activity, blood analysis, fitness (aerobic, strength and flexibility), and postural. From these baseline assessments the participants are able to choose follow-up interventions involving supervised exercises combined with weekly counseled (or supervised) dietary interventions (LiSM program). The follow-up assessments occur every 10 weeks. The assessments as well as physical exercises and dietary interventions are conducted by graduate students holding institutional fellowships. The program is opened for beginners three times a year and is free of charge for the first 10 weeks [15,38].

\section{Measurements}

Physical activity level (PAL), socio-demographic characteristics (gender, age, marital status, family income and education) and health status are obtained by applying the International Physical Activity Questionnaire (IPAQ version 8 - long form) [39]. Marital status was classified as married (married and stable union) and unmarried (single, widowed, divorced, and separated). The schooling level was classified as fundamental complete and incomplete, secondary education and higher. Family income ranked from up to five minimum wages $(<5 \mathrm{SM})$ or greater/equal to five times the minimum wage ( $25 \mathrm{SM}$ ). Health perception was rated as good (excellent, 
very good or good) or bad (fair and poor). Body weight and height measurements are taken [40] with subsequent calculation of body mass index $\left(B M I=\mathrm{kg} / \mathrm{m}^{2}\right)$ classified as normal weight when up to $24.9 \mathrm{~kg} / \mathrm{m}^{2}$, overweight 25 up to $29.9 \mathrm{~kg} / \mathrm{m}^{2}$ and obese with values greater than $30 \mathrm{~kg} / \mathrm{m}^{2}$ [41]. The waist circumference (WC) is measured with millimeter tape inextensible and inelastic on the midpoint between the last intercostal space and iliac crest. The value of $88 \mathrm{~cm}$ is adopted as cutoff for abdominal obesity [40]. Body muscle and fat composition is performed in the supine position by bioelectrical impedance (BIA) (Biodinâmics ${ }^{\circledR}$, model 450, USA) with the calculation of muscle mass by the equation proposed by [42] calculated as body mass index (IMM) as proposed by [43]. Sarcopenia classification adopted for women was: Normal-IMM $>5.45 \mathrm{~kg} / \mathrm{m}^{2}$, Sarcopenia - IMM $\leq 5.45 \mathrm{~kg} / \mathrm{m}^{2}$ [44]. The percentage of female fat used as normal is $20-35 \%[45]$.

\section{Blood pressure}

An initial medical screening is carried out to exclude those individuals with severe hypertension, diabetes mellitus, cardiopulmonary, renal, hepatic, and severe orthopedic diseases. The evaluation of the PA is held with the subject seated, following the recommendations of the VI Brazilian Guidelines on Hypertension (SBC, 2010). Resting blood pressure (BP) is measured using a digital automatic oscillometric device (Omron, USA). As published earlier [1,5], these measurements were superimposed to parallel measurements taken with a standard mercury manometer in the initial screening period and, there were no significant intra-and inter-device reading deviation.

\section{Lifestyle modification protocol}

Nutritional counseling is applied weekly through lectures in groups with relevant nutritional context in which subjects were comprised. Physical Exercises Protocols consisted by supervised exercise sessions in accordance with the ACSM's guidelines for exercise prescription and treatment of chronic non-communicable diseases [46].

\section{Physical exercises protocols}

1) Academy exercises (PAc) with elderly-adapted weight-liftequipments distributed in a circuit sequence. Each $60 \mathrm{~min}$. supervised- session was composed by $10 \mathrm{~min}$. dynamic- warm up/stretching, 40min. of resistance training (3 sets of 8-12 repetitions at $60 \%-70 \% 1 \mathrm{RM}$ each exercise) finishing up with $10 \mathrm{~min}$. cool down- stretching. The strength training sessions were preceded by 2 wk-exercise familiarization and $1 \mathrm{RM}$ test realization. Daily sessions were conducted three days a week, alternately.

2) Daily-Mixed Exercises (PMi): The physical exercise protocol is composed by daily sessions of $90 \mathrm{~min}$, including $10 \mathrm{~min}$ dynamic- warm up/ stretching, $30 \mathrm{~min}$ walking $\left(60-80 \% \mathrm{VO}_{2 \text { max }}\right)$, 40 min strength in academy (3x 8-12 rep, 60-70\% 1RM) and 10min stretching and cool down. Strength exercises were alternated in different days, for upper and lower limbs. Vo2max. Is determined by the Balke's protocol in electronic treadmill [47]. The mixed-exercise protocol should be attended three or more sessions during the week.

3) Alternately concurrent exercises (PMiA): subjects were submitted to walking and stretching (aerobic activities, at Mondays, Wednesdays and Fridays) and resistance training (weight-lifting activities, Tuesdays and Thursdays).

4) HIT (PHit): The twice a week, 60min. whole exercise-protocol was composed by initial ( 5 minutes) and final (10 minutes) stretching; the latter was intended as an aid to cool down for baseline-heart rate recover. The $43 \mathrm{~min}$. high-intensity interval training on treadmill included 10 minutes of warm-up at $70 \%$ of maximum heart rate (HR max), followed by 4 series of 4 minutes each on $90 \%$ HR max with 3-min intervals between series for active recovery at $70 \%$ of FC max. [48]. 
5) Hydrogymnastics (PHy): 60 minutes of exercise predominantly aerobic in a 29o.C swimming pool, compose by $10 \mathrm{~min}$. warm up, $10 \mathrm{~min}$. stretching, $30 \mathrm{~min}$. principal and ending up with $10 \mathrm{~min}$. slowing down towards heart rate stabilization. Exercises were conducted twice a week in alternated days.

\section{Statistical Analysis}

Results were expressed as mean and standard deviation for continuous variables and frequency and percentage for categorical variables. The proportion comparisons were done by chi-square test $(\chi 2)$, the ANOVA repeated measure for symmetric quantitative variables and the range model repeated measures for the asymmetric quantitative. SAS for Windows, version 9.1 was used with a significance level of $5 \%$ or corresponding p-value.

\section{Results}

\section{Experiment 1}

Sample composed by 606 individuals, aged $55.5 \pm 10.8$ years, $88 \%$ females, marrieds (88\%), low-socioeconomic (92\%) and elementary schooling (80\%), consuming inadequate diet (95\%), 91\% referring the WHO (2010) recommended physical activity but with $80 \%$ overweight. Regarding the physical fitness the sample presented, at baseline, 63\% good aerobic (VO2max.) and 78\% good (hand-grip) strength fitness. The found hypertension rate was $41,4 \%$. There were no differences among protocols for all these variables, at baseline (Table 1).

\begin{tabular}{|c|c|c|c|c|c|}
\hline Variables/Protocols & PHy & PHit & PAC & PMi & TOTAL \\
\hline Age (years) & $60.2 \pm 10.4$ & $53.3 \pm 8.8$ & $57.5 \pm 12.7$ & $53.4 \pm 10.2$ & $55.5 \pm 10.8$ \\
\hline$<60$ & $32(50.8 \%)$ & $36(83.7 \%)$ & $29(58 \%)$ & $98(67.1 \%)$ & $195(64.6 \%)$ \\
\hline$\geq 60$ & $31(49.2 \%)$ & $7(16.3 \%)$ & $21(42 \%)$ & $48(32.9 \%)$ & $107(354 \%)$ \\
\hline \multicolumn{6}{|l|}{ Gender } \\
\hline Female & $62(98.4 \%)$ & $43(100 \%)$ & $39(78 \%)$ & $122(83.5 \%)$ & $266(88.1 \%)$ \\
\hline Male & $1(1.6 \%)$ & $0(0 \%)$ & $11(22 \%)$ & $24(16.5 \%)$ & $36(11.9 \%)$ \\
\hline \multicolumn{6}{|l|}{ Marital status } \\
\hline Married & $54(85.7 \%)$ & $34(79.1 \%)$ & $43(86 \%)$ & $110(75.3 \%)$ & $241(79.8 \%)$ \\
\hline Non-married & $9(14.3 \%)$ & $9(20.9 \%)$ & $7(14 \%)$ & $36(24.7 \%)$ & $61(20.2 \%)$ \\
\hline \multicolumn{6}{|l|}{ Family income } \\
\hline Up to 5 minimum wage & $60(95.2 \%)$ & $38(88.4 \%)$ & $41(82 \%)$ & $140(95.9 \%)$ & $279(92.4 \%)$ \\
\hline$>5$ minimum wage & $3(4.8 \%)$ & $5(11.6 \%)$ & $9(18 \%)$ & $6(4.1 \%)$ & $23(7.6 \%)$ \\
\hline \multicolumn{6}{|l|}{ Schooling } \\
\hline Elementary & $55(87.3 \%)$ & $36(83.7 \%)$ & $40(80 \%)$ & $110(75.3 \%)$ & $241(79.8 \%)$ \\
\hline High school/college & $8(12.7 \%)$ & $7(16.3 \%)$ & $10(20 \%)$ & $36(24.7 \%)$ & $61(20.2 \%)$ \\
\hline \multicolumn{6}{|l|}{ Health Eating Index } \\
\hline Inadequate & $38(100 \%)$ & $26(96.3 \%)$ & $30(90.9 \%)$ & $118(94.4 \%)$ & $212(95.1 \%)$ \\
\hline Adequate & $0(0 \%)$ & $1(3.7 \%)$ & $3(9.1 \%)$ & $7(5.6 \%)$ & $11(4.9 \%)$ \\
\hline Body weight & & & & & \\
\hline Overweight & $54(85.7 \%)$ & $36(83.7 \%)$ & $36(72 \%)$ & $117(80.1 \%)$ & $243(80.5 \%)$ \\
\hline Eutrophy & $9(14.3 \%)$ & $7(16.3 \%)$ & $14(28 \%)$ & $29(19.9 \%)$ & $59(19.5 \%)$ \\
\hline Physical activity level & & & & & \\
\hline Recommended & $58(92.1 \%)$ & $41(95.4 \%)$ & $44(88 \%)$ & $132(90.4 \%)$ & $275(91.1 \%)$ \\
\hline Lower than recommended & $5(7.9 \%)$ & $2(4.6 \%)$ & $6(12 \%)$ & $14(9.6 \%)$ & $27(8.9 \%)$ \\
\hline Hand grip strength & & & & & \\
\hline Low & $15(23.8 \%)$ & $5(11.6 \%)$ & $10(20 \%)$ & $37(25.3 \%)$ & $67(22.2 \%)$ \\
\hline Good & $48(76.2 \%)$ & $38(88.4 \%)$ & $40(80 \%)$ & $109(74.7 \%)$ & $235(77.8 \%)$ \\
\hline Cardiorespiratory fitness & & 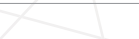 & & & \\
\hline Low & $4(25 \%)$ & $7(21.9 \%)$ & $6(50 \%)$ & $20(513 \%)$ & $37(37.4 \%)$ \\
\hline Good & $12(75 \%)$ & $25(78.1 \%)$ & $6(50 \%)$ & $19(48.7 \%)$ & $62(62.6 \%)$ \\
\hline
\end{tabular}


The characteristics of the used protocols are in table 2. All protocols were considered as the moderate intensity. Only PMi was longer-length than the others, consequently offered higher volume and energy expenditure than the others.

Ten-wk exercise training improved V02max. Similarly in all protocols while hand grip increased only in PAc. The average SBP and DBP were both reduced by PHy and only SBP by the PMi (Table 3). Overall, hypertension rate was reduced from $41,4 \%$ to $25,5 \%$.

Analysis of categorized variables showed, after all adjustments that hypertension rate was reduced by the protocols PAc, PMi and PHy (Table 4).

\section{Experiment 2}

Baseline data from 124 subjects enrolled to the Move for Health program during the 2011-2012 period fullfiled the inclusion criteria for this experiment. Sample was predominantly female ( $81.5 \%), 84.7 \%$ overweight ( $50 \%$ obese), $27.4 \%$ hypertensive. The distribution among protocols was similar for the studied variables (Table 5).

After the 24wk intervention the hypertension rate was reduced by $21.3 \%$ in the PMiA, $18.8 \%$ in the PHy and $16.6 \%$ in the PAc. The SBP was reduced similarly, by protocols PAc $(9.4 \mathrm{mmHg})$ and $\mathrm{PMiA}(6.3 \mathrm{mmHg})$ whose effects were maintained after the adjustments for the confounded variables(Table 6). The DBP was reduced (5.6 $\mathrm{mmHg}$ ) only by PMiA, under all adjustment conditions (Table 7).

\begin{tabular}{|c|c|c|c|c|}
\hline \multicolumn{2}{|c|}{ Table 2: The characteristics of the used protocols. } & \multicolumn{3}{l|}{} \\
\hline Variables/Protocols & PHy & PHit & PAc & PMi \\
\hline Session (minutes) & 60 & 60 & 3 & 3 a 5 \\
\hline Week frequency (day/week) & 2 & 2 & Moderate & Moderate \\
\hline Intensity & Moderate & Moderate/Vigorous & 180 & 270 to 450 \\
\hline Total Volume (min/week) & 120 & 120 & 272.5 & 371.5 \\
\hline Energy Expenditure (METs/session) & 200 & 248.1 &
\end{tabular}

$\mathrm{PHy}=$ hydrogymnastic; PHit=treadmill high intensity; PAc=academy; PMi=mixed academy/endurance exercises; *Ainsworth et al. [53].

Table 3: The effects of 10-wk intervention with different protocols of physical exercises.

\begin{tabular}{|c|c|c|c|c|c|}
\hline & & \multicolumn{4}{|c|}{ Exercise Protocols } \\
\hline Variables & & PHy & PHit & PAC & PMi \\
\hline \multirow{2}{*}{ Hand grip strength $(\mathrm{kg})$} & MO & $26.1 \pm 6.5 \mathrm{aB}$ & $29.5 \pm 6.0 \mathrm{aA}$ & $31.7 \pm 12.9 \mathrm{aA}$ & $29.6 \pm 10.6$ aA \\
\hline & M1 & $26.4 \pm 6.7 \mathrm{aB}$ & $29.9 \pm 5.9 \mathrm{aC}$ & $34.6 \pm 13.3 \mathrm{bA}$ & $31.2 \pm 10.0 \mathrm{bAC}$ \\
\hline \multirow{2}{*}{ V02max (ml/kg/min) } & M0 & $27.9 \pm 5.2 \mathrm{aA}$ & $32.3 \pm 5.4 \mathrm{aB}$ & $31.8 \pm 8.9$ aAB & $29.9 \pm 5.9$ aAB \\
\hline & M1 & $32.7 \pm 4.9 \mathrm{bA}$ & $37.2 \pm 5.9 \mathrm{bB}$ & $35.1 \pm 9.2 \mathrm{bAB}$ & $33.5 \pm 6.2 \mathrm{bA}$ \\
\hline \multirow{2}{*}{$\mathrm{SBP}(\mathrm{mmHg})$} & MO & $127.6 \pm 16.5 \mathrm{aA}$ & $117.6 \pm 12.9 \mathrm{aB}$ & $121.9 \pm 15$ aABC & $122.6 \pm 17.4 \mathrm{aC}$ \\
\hline & M1 & 121.2 $\pm 17.9 \mathrm{bA}$ & $118.2 \pm 14.8 \mathrm{aA}$ & $120.1 \pm 16.8$ aA & $120.0 \pm 15.3 \mathrm{bA}$ \\
\hline \multirow{2}{*}{$\mathrm{DBP}(\mathrm{mmHg})$} & MO & $80.4 \pm 11.1 \mathrm{aA}$ & $74.8 \pm 11.7 \mathrm{aB}$ & $77.9 \pm 10.6$ aAB & $78.4 \pm 1.6 \mathrm{aAB}$ \\
\hline & M1 & $79.1 \pm 13.2 \mathrm{aA}$ & $75.7 \pm 11.7$ aAB & $76.3 \pm 11.1 \mathrm{aAB}$ & $75.6 \pm 10.1 \mathrm{bB}$ \\
\hline
\end{tabular}

Mean+_SD, PHy=hydrogymnastic; PHit=treadmill high intensity; PAc=academy; $P M i=m i x e d$ academy/endurance exercises; Mo=baseline; $\mathrm{M} 1=$ =after 10 weeks; $\mathrm{SBP}=$ systolic blood pressure; $\mathrm{DBP}=$ diastolic blood pressure.

\begin{tabular}{|c|c|c|c|c|c|c|c|c|c|c|c|c|}
\hline & \multicolumn{2}{|c|}{ PHy } & \multirow[b]{2}{*}{$\mathbf{p}$} & \multicolumn{2}{|c|}{ PHit } & \multirow[b]{2}{*}{$\mathbf{p}$} & \multicolumn{2}{|c|}{ PAC } & \multirow[b]{2}{*}{ p } & \multicolumn{2}{|c|}{ PMi } & \multirow[b]{2}{*}{$\mathbf{p}$} \\
\hline & MO & M1 & & MO & M1 & & MO & M1 & & MO & M1 & \\
\hline \multicolumn{13}{|l|}{$\begin{array}{c}\text { Blood } \\
\text { pressure }\end{array}$} \\
\hline High & $\begin{array}{c}36 \\
(57.1 \%)\end{array}$ & $\begin{array}{c}20 \\
(31.8 \%)\end{array}$ & \multirow{2}{*}{0.004} & $\begin{array}{c}8 \\
(18.6 \%)\end{array}$ & $\begin{array}{c}9 \\
(20.9 \%)\end{array}$ & \multirow{2}{*}{0.78} & $\begin{array}{c}18 \\
(36 \%)\end{array}$ & 9 (18\%) & \multirow{2}{*}{0.04} & $\begin{array}{c}63 \\
(43.2 \%)\end{array}$ & $\begin{array}{c}39 \\
(26.7 \%)\end{array}$ & \multirow{2}{*}{0.003} \\
\hline Normal & $\begin{array}{c}27 \\
(42.9 \%)\end{array}$ & $\begin{array}{c}43 \\
(68.2 \%)\end{array}$ & & $\begin{array}{c}35 \\
(81.4 \%)\end{array}$ & $\begin{array}{c}34 \\
(79.1 \%)\end{array}$ & & $\begin{array}{c}32 \\
(64 \%)\end{array}$ & $\begin{array}{c}41 \\
(82 \%)\end{array}$ & & $\begin{array}{c}83 \\
(56.8 \%)\end{array}$ & $\begin{array}{c}107 \\
(73.3 \%)\end{array}$ & \\
\hline & $\mathrm{N}=63$ & $N=63$ & & $\mathrm{~N}=43$ & $N=43$ & & $N=50$ & $N=50$ & & $N=146$ & $N=146$ & \\
\hline
\end{tabular}


Table 5: Age, anthropometric and vascular variables distribution among physical-exercises protocols.

\begin{tabular}{|c|c|c|c|c|c|}
\hline & PAc & PMiA & PMi & PHy & $p$ valor \\
\hline & $(n=24)$ & $(n=75)$ & $(n=9)$ & $(n=16)$ & \\
\hline Age (yrs) & $55.0 \pm 11.1$ & $52.7 \pm 9.0$ & $49.0 \pm 8.0$ & $58.4 \pm 10.5$ & 0.0728 \\
\hline Body wt (kg) & $79.0 \pm 17.5$ & $79.7 \pm 21.3$ & $84.6 \pm 17.2$ & $76.6 \pm 15.9$ & 0.8088 \\
\hline Height (m) & $1.63 \pm 0.1$ & $1.59 \pm 0.1$ & $1.62 \pm 0.1$ & $1.61 \pm 0.1$ & 0.1597 \\
\hline BMI & $28.9 \pm 5.1$ & $31.5 \pm 6.8$ & $32.1 \pm 5.7$ & $29.6 \pm 6.2$ & 0.2246 \\
\hline WC & $97.3 \pm 11.5$ & $98.6 \pm 17.0$ & $99.2 \pm 11.5$ & $95.0 \pm 15.7$ & 0.8477 \\
\hline$\% B F$ & $32.7 \pm 9.5$ & $36.7 \pm 10.5$ & $36.7 \pm 9.2$ & $37.6 \pm 10.5$ & 0.2628 \\
\hline MM & $24.2 \pm 7.5$ & $20.5 \pm 4.2$ & $21.8 \pm 5.9$ & $21.9 \pm 4.4$ & 0.1976 \\
\hline MMI & $9.0 \pm 2.1$ & $7.9 \pm 1.2$ & $8.5 \pm 1.6$ & $8.3 \pm 1.0$ & 0.2456 \\
\hline SBP & $126.0 \pm 16.0$ & $122.1 \pm 16.5$ & $124.0 \pm 16.0$ & $122.9 \pm 10.5$ & 0.8572 \\
\hline DBP & $80.6 \pm 11.2$ & $78.6 \pm 11.4$ & $79.0 \pm 10.5$ & $83.1 \pm 11.3$ & 0.6748 \\
\hline
\end{tabular}

Mean+_SD, PHy=hydrogymnastic; PAc=academy; PMi=daily mixed=academy/endurance exercises; $\mathrm{PMiA}=\mathrm{PMi}$ alternating days for academy and endurance; Mo=baseline; $M 1=$ after 10 weeks; $S B P=$ systolic blood pressure; $\mathrm{DBP}=$ diastolic blood pressure; $\mathrm{BMI}=$ body mass index; \%BF=\% body fat; $\mathrm{MM}=$ muscle mass; $\mathrm{MMI}=$ muscle mass index; wc=waist circumference.

Table 6: Regression analysis of the categorized variables of systolic blood pressure in each exercise protocol after 10 weeks of intervention.

\begin{tabular}{|c|c|c|c|c|c|}
\hline Model & & PAc & PMiA & PMi & PHy \\
\hline \multirow{2}{*}{1} & MO & $126.0 \pm 16.0 \mathrm{aA}$ & $125.0 \pm 16.0 \mathrm{aA}$ & $122.9 \pm 10.5 \mathrm{aA}$ & $122.1 \pm 16.5 \mathrm{aA}$ \\
\hline & M1 & $116.6 \pm 14.1 \mathrm{bA}$ & $118.7 \pm 10.8 \mathrm{bA}$ & $121.6 \pm 17.2 \mathrm{aA}$ & $121.9 \pm 10.8 \mathrm{aA}$ \\
\hline \multirow{2}{*}{2} & MO & $126.0 \pm 16.0 \mathrm{aA}$ & $125.0 \pm 16.0 \mathrm{aA}$ & $122.9 \pm 10.5 \mathrm{aA}$ & $122.1 \pm 16.5 \mathrm{aA}$ \\
\hline & M1 & $116.6 \pm 14.1 \mathrm{bA}$ & $118.6 \pm 10.8 \mathrm{bA}$ & $121.6 \pm 17.2 \mathrm{aA}$ & $121.9 \pm 10.8 \mathrm{aA}$ \\
\hline \multirow{2}{*}{3} & MO & $126.0 \pm 16.0 \mathrm{aA}$ & $121.9 \pm 10.8 \mathrm{aA}$ & $122.9 \pm 10.5 \mathrm{aA}$ & $122.1 \pm 16.5 \mathrm{aA}$ \\
\hline & M1 & $116.6 \pm 14.1 \mathrm{bA}$ & $118.6 \pm 10.8 \mathrm{bA}$ & $121.6 \pm 17.2 \mathrm{aA}$ & $121.9 \pm 10.8 \mathrm{aA}$ \\
\hline \multirow{2}{*}{4} & MO & $126.0 \pm 16.0 \mathrm{aA}$ & $125.0 \pm 16.0 \mathrm{aA}$ & $122.9 \pm 10.5 \mathrm{aA}$ & $122.1 \pm 16.5 \mathrm{aA}$ \\
\hline & M1 & $116.6 \pm 14.1 \mathrm{bA}$ & $118.6 \pm 10.8 \mathrm{bA}$ & $121.6 \pm 17.2 \mathrm{aA}$ & $121.9 \pm 10.8 \mathrm{aA}$ \\
\hline \multirow{2}{*}{5} & M0 & $126.0 \pm 16.0 \mathrm{aA}$ & $125.0 \pm 16.0 \mathrm{aA}$ & $122.9 \pm 10.5 \mathrm{aA}$ & $122.1 \pm 16.5 \mathrm{aA}$ \\
\hline & M1 & $116.6 \pm 14.1 \mathrm{bA}$ & $118.6 \pm 10.8 \mathrm{bA}$ & $121.6 \pm 17.2 \mathrm{aA}$ & $121.9 \pm 10.8 \mathrm{aA}$ \\
\hline \multirow{2}{*}{6} & MO & $126.0 \pm 16.0 \mathrm{aA}$ & $125.0 \pm 16.0 \mathrm{aA}$ & $122.9 \pm 10.5 \mathrm{aA}$ & $122.1 \pm 16.5 \mathrm{aA}$ \\
\hline & M1 & $116.6 \pm 14.1 \mathrm{bA}$ & $118.6 \pm 10.8 \mathrm{bA}$ & $121.6 \pm 17.2 \mathrm{aA}$ & $121.9 \pm 10.8 \mathrm{aA}$ \\
\hline \multirow{2}{*}{7} & MO & $126.0 \pm 16.0 \mathrm{aA}$ & $125.0 \pm 16.0 \mathrm{aA}$ & $122.9 \pm 10.5 \mathrm{aA}$ & $122.1 \pm 16.5 \mathrm{aA}$ \\
\hline & M1 & $116.6 \pm 14.1 \mathrm{bA}$ & $118.6 \pm 10.8 \mathrm{bA}$ & $121.6 \pm 17.2 \mathrm{aA}$ & $121.9 \pm 10.8 \mathrm{aA}$ \\
\hline
\end{tabular}

Mo=baseline; M1=after $10 \mathrm{wks} ; \mathrm{a}, \mathrm{b}: \mathrm{p}<0.05 \mathrm{M0xM1;A,B,C}: \mathrm{p}<0.05$ among protocols; Model $1=$ crude; Model 2=adjusted for age and gender; Model 3=model 2+body mass index; Model 4=model 3+waist circumference; Model 5=adjusted for age, gender and muscle mass; Model 6=model 5+body mass index; Model 7=adjusted for age, gender, muscle mass and waist circumference.

Table 7: Regression analysis of the categorized variables of diastolic blood pressure in each exercise protocol after 10 weeks of intervention.

\begin{tabular}{|c|c|c|c|c|c|}
\hline Model & & PAc & PMiA & PMi & PHy \\
\hline \multirow{2}{*}{1} & M0 & $80.6 \pm 11.2 \mathrm{aA}$ & $79.0 \pm 10.5 \mathrm{aA}$ & $83.1 \pm 11.3 \mathrm{aA}$ & $78.6 \pm 11.4 \mathrm{aA}$ \\
\cline { 2 - 6 } & M1 & $77.0 \pm 8.4 \mathrm{aA}$ & $73.4 \pm 8.0 \mathrm{bA}$ & $84.0 \pm 7.9 \mathrm{aB}$ & $76.0 \pm 9.8 \mathrm{aA}$ \\
\hline \multirow{2}{*}{2} & M0 & $80.6 \pm 11.2 \mathrm{aA}$ & $79.0 \pm 10.5 \mathrm{aA}$ & $83.1 \pm 11.3 \mathrm{aA}$ & $78.6 \pm 11.4 \mathrm{aA}$ \\
\cline { 2 - 6 } & M1 & $77.9 \pm 8.4 \mathrm{aA}$ & $73.4 \pm 8.0 \mathrm{bA}$ & $84.0 \pm 7.9 \mathrm{aB}$ & $76.0 \pm 9.8 \mathrm{aA}$ \\
\hline \multirow{2}{*}{3} & M0 & $80.6 \pm 11.2 \mathrm{aA}$ & $76.0 \pm 9.8 \mathrm{aA}$ & $83.1 \pm 11.3 \mathrm{aA}$ & $78.6 \pm 11.4 \mathrm{aA}$ \\
\cline { 2 - 6 } & M1 & $77.0 \pm 8,4 \mathrm{aA}$ & $73.4 \pm 8,0 \mathrm{bB}$ & $84.0 \pm 7,9 \mathrm{aC}$ & $76.0 \pm 9,8 \mathrm{aABC}$ \\
\hline \multirow{2}{*}{4} & M0 & $80.6 \pm 11.2 \mathrm{aA}$ & $79.0 \pm 10.5 \mathrm{aA}$ & $83.1 \pm 11.3 \mathrm{aA}$ & $78.6 \pm 11.4 \mathrm{aA}$ \\
\cline { 2 - 6 } & M1 & $77.0 \pm 8.4 \mathrm{aA}$ & $73.4 \pm 8.0 \mathrm{bB}$ & $84.0 \pm 7.9 \mathrm{aC}$ & $76.0 \pm 9.8 \mathrm{aAB}$ \\
\hline \multirow{2}{*}{5} & M0 & $80.6 \pm 11.2 \mathrm{aA}$ & $79.0 \pm 10.5 \mathrm{aA}$ & $83.1 \pm 11.3 \mathrm{aA}$ & $78.6 \pm 11.4 \mathrm{aA}$ \\
\cline { 2 - 6 } & M1 & $77.0 \pm 8.4 \mathrm{aA}$ & $73.4 \pm 8.0 \mathrm{bA}$ & $84.0 \pm 7.9 \mathrm{aB}$ & $76.0 \pm 9.8 \mathrm{aA}$ \\
\hline \multirow{2}{*}{6} & M0 & $80.6 \pm 11.2 \mathrm{aA}$ & $79.0 \pm 10.5 \mathrm{aA}$ & $83.1 \pm 11.3 \mathrm{aA}$ & $78.6 \pm 11.4 \mathrm{aA}$ \\
\cline { 2 - 6 } & M1 & $77.0 \pm 8.4 \mathrm{aA}$ & $73.4 \pm 8.0 \mathrm{bB}$ & $84.0 \pm 7.9 \mathrm{aA}$ & $76.0 \pm 9.8 \mathrm{aAB}$ \\
\hline \multirow{2}{*}{7} & M0 & $80.6 \pm 11.2 \mathrm{aA}$ & $79.0 \pm 10.5 \mathrm{aA}$ & $83.1 \pm 11.3 \mathrm{aA}$ & $78.6 \pm 11.4 \mathrm{aA}$ \\
\cline { 2 - 6 } & M1 & $77.0 \pm 8.4 \mathrm{aA}$ & $73.4 \pm 8.0 \mathrm{bB}$ & $84.0 \pm 7.9 \mathrm{aC}$ & $76.0 \pm 9.8 \mathrm{aAB}$ \\
\hline
\end{tabular}

Mo=baseline; M1=after $10 \mathrm{wks;a,b:} \mathrm{p<0.05} \mathrm{M0xM1;} \mathrm{A,B,C} \mathrm{:p<0.05} \mathrm{among} \mathrm{protocols;} \mathrm{Model} \mathrm{1=crude;} \mathrm{Model} \mathrm{2=adjusted}$ for age and gender; Model 3=model 2+body mass index; Model 4=model 3+waist circumference; Model 5=adjusted for age, gender and muscle mass; Model 6=model 5+body mass index; Model 7=adjusted for age, gender, muscle mass and waist circumference. 


\section{Discussion}

The adult population sampled here lived in a middle size city in the richest state of the nation therefore, fully accessed to the SUS System and additionally, all having the health privileges for being domiciled under the umbrella of a local Public Medical School. Even though, the found undiagnosed hypertension was 9.8\% [14] and the prevalence of hypertension varied from 28\%(experiment 2)), 42\%(experiment 1)), $51.2 \%[14]$ to $61.3 \%$ [5] by using clinical setpoints of SBP >_140mmHG and DBP >_90mmHg.

In 2002, the distribution of hypertensive patients by the Brazilian guidelines varied from $53.3 \%$ stage 1 to $35.7 \%$ stage 2 and $11 \%$ stage 3 [49]. In 2014, baseline findings from ELSA-Brasil study show a frequency of $35.8 \%$ high blood pressure [4]. The free demand probably would explain why our higher prevalence, comparatively to the general population. Afterall, as a chronic disease, hypertension is "silent", slow in its progress and long in its continuance". Our undiagnosed hypertension rate was $9.8 \%$ [14].

The diagnosis of hypertension by the high blood pressure "setpoint" follows the homeostasis model [31]. By decreasing the hypertensive setpoint policy from the clinical $140 \times 90 \mathrm{mmHg}$ to a recommended $130 \mathrm{x} 85 \mathrm{mmHg}$ (NCEP-ATP III) or the recently recommended $120 \times 80 \mathrm{mmHg}$ (that would increase hypertension rate by $5 \%$ ), it accomplishes the goal of the "industry of the disease" by terrorizing the population to be medicated earlier by prescribers and, therefore, increasing the consume of pharmaceutical-industrialized drugs (NCEP ATP III, 2002).

Medication cannot be preventive, so it must follow clinical signs. Hypertension, as chronic disease, does not cross the "clinical horizon" so, it is not clinically manifested, during the natural course of the disease. Consequently, the reaction of the biomedical establishment has primarily been to apply modern technologies to stabilize overt clinical problems (e.g., secondary and tertiary prevention) [50].

The homeostasis definition of holding constant a controlled variable by sensing its deviation from a "setpoint" and feeding back to correct the error, has dominated physiology and medicine since Claude Bernard declared: "All the vital mechanisms... have only one object - to preserve constant the conditions of ... the internal environment". There since, homeostasis model has contributed immeasurably to the theory and practice of scientific medicine [31].

By treating hypertension with drugs that target the three primary effectors of elevated pressure renders that variable insensitive to predicted need, which oposes the whole point of physiological regulation. For these reasons, less than $25 \%$ of hypertensive patients in the US are controlled. The major problem is considered to be "the very high rate of discontinuance or change in medications: $50-70 \%$... within the first six months... "[36]. These high discontinuance rates are considered to reflect, among other factors, "a combination of adverse drug effects, cost of drugs, and poor efficacy" [36]. Consequently despite their remarkable ingenuity, 30 years of low-level pharmacological treatments for hypertension have not worked [31]. The proportion of medicated non-controlled hypertension was $28.8 \%$ [14].

Definitely, homeostasis model cannot explain essential hypertension because it attributes all pathology to a "defect". Someway differently, the allostasis model suggests that there is no defect. More parsimoniously, it proposes that hypertension emerges as the concerted response of multiple neural effectors to prediction of a need for vigilance. When this prediction is sustained, all the effectors, both somatic and neural, adapt progressively to life at high pressure. Thus, over decades the constant call for vigilance adapts arterial muscle and carotid sinus to thicken and stiffen so that pressure rarely returns to normal levels [31]. 
In our studies about possible vigilance factors on hypertension we have not found the socieconomic characteristics of lower schooling and low income. These effects might be minimized by the fact that, in Brazil, the medication is free of charge. Moreover, our medical Institution conducts a specific program to attend all registered hypertensive subjects providing anti-hypertensive drugs. Thereby, it is hard to understand why $9.8 \%$ of the hypertensive patients were unaware of their abnormality (undiagnosed hypertension). On the other hand, lower schooling and socioeconomic status might influence food intake and, dietary quality that was proved as strong determinant of blood hypertension with higher blood pressure being associated with a dietary characteristics of high "processed pattern" (high sodium, low potassium and calcium, high sugar, low fiber) [14].

The unexpected high rate of medicated-non controlled hypertensive subjects leads to the hypothesis that anti-hypertensive drugs were not working reasonably and their users were not satisfied with them. Therefore, one might speculate the existence of an ongoing cultural resistance to the usual drug treatment and, an arising attention for alternative non-drug procedures. Based on this, our LiSM intervention would be one of these alternatives. However, to adopt our LiSM program the patient must be fit for physical exercises. The studied medicated non-controlled patients referred themself as being in excellent or good state of health (92\%) showing moderate status of physical activity (53\%) with $85.1 \%$ full filing the WHO's recommendations for being active individual [14].

In the implementation of effective population-based strategies, diet and physical exercise are the pillars of treatment. Exercise has the most potent effect on endotheliumdependent vasodilatation. The endothelium -derived nitric oxide (eNO) is thought to be necessary to maintain an adequate vascular response to increased bloodflow demands during exercise. For though, shear stress is an important component of exercise that affects vascular NO concentration, and increases the velocity of the endothelial high-affinity/low-capacity transport system for L-arginine [51]. Muscular contraction dependent $\left[\mathrm{Ca}^{++}\right]$also modulates eNOS activity but shear stress lead to eNOS phosphorylation on serine residues independent from increases in $\left[\mathrm{Ca}^{++}\right][52-$ 62].

In our set of experiments, high blood pressure responded to all exercise protocols, irrespective of weight loss. However, the reduction of hypertension by LiSM was followed by increased aerobic conditioning and reduced intake of processed foods along with decreased values of BMI, abdominal fatness, insulin resistance, proinflammatory and peroxydative activities [1].

Regarding the hypertension response to the type of exercise, it was demonstrated by the present results, as time-dependent for isolated walking-jogging or strength training and, abbreviated by combining both. Short-period responsiveness could be achieved by either combined (strength-endurance) or hydrogymnastic exercises.

Finally, mostly of the medicated non-controlled patients were from the lowincome range (less than US\$1,500 a month) and though probably under the Brazilian rules for free of charge medications. Excluding the economical reasons, the two other important points would be their self-perception of being in an excellent/good health status, meaning" I'm feeling good so I'm cured so I don't need medication anymore" and/or they were younger (60\% under $60 \mathrm{yrs})$ and physically active and (56.8\%) able for weekly moderate- activities. In the later instance, the patients probably realized the beneficial effects of being healthy without medicines (and their unpleasant side effects) and looked for the lifestyle modification alternative such as our LiSM program.

On the economic effectiveness side of our LiSM, the Brazilian government spends, in average, US\$ $39.50 /$ month for each diagnosed hypertensive subject [9], US\$ 474 
a year ending up to the yearly sum of US $\$ 17.3$ billion spent with anti-hypertensive medications! Moreover, we found rates of medicated-non controlled hypertensives as $65.2 \%$ and $67 \%$ for diastolic and systolic BP, respectively. If applied nationwide, these rates would mean a wasting of more than US\$ 14 billion spent with medications that are not working properly! On the other side, the net effectiveness of our 10wkLiSM in normalizing SBP hypertension was $8.5 \%$. If applied this figure nationwide, we would normalize 3.1 million of hypertensive citizens, at an economic costs of US\$ 1.47 billion! [14], which could be amplified to US\$ 14.2 billion if LiSM is extended to 8mo. and normalizing $31.6 \%$ of hypertensive [5]. Thus, exercise training is a time- and typedependent tool feasible, costless and scientific-based rheostatic-allostatic alternative for the current "sick-care" drug-dependent homeostatic approach to hypertension medicare.

\section{References}

1. Burini RC, Kano HT, Burini FHP, McLellan KCP. Metabolic Syndrome-From the Mismatched Evolutionary Genome with the Current Obesogenic Environment to the Lifestyle Modification as a Primary Care of Free-Living Adults in a Brazilian Community. In: Jody Morton. editor. Metabolic Syndrome: Clinical Aspects, Management Options a53610-723-4nd Health Effects. Nova Science Publ. 2017; 978-981.

2. Zhu Y, Bian Z, Lu P, Karas RH, Bao L, et al. Abnormal vascular function and hypertension in mice deficient in estrogen receptor beta. Science. 2002; 295: 505-508. Ref.: https://goo.gl/4CTp8z

3. Kearney PM, Whelton M, Reynolds K, Whelton PK, He J. Worldwide prevalence of hypertension: a systematic review. J Hypertens. 2004; 22: 11-19. Ref.: https://goo.gl/SrysgB

4. Schmidt MI, Duncan BB, Mill JG, Lotufo PA, Chor D, et al. Cohort Profile: Longitudinal Study of Adult Health (ELSA-Brasil). Int J Epidemiol. 2015; 68-75. Ref.: https://goo.gl/ooYsZp

5. Burini RC, Simonetti LA, Maesta N, Waib PH. Efficiency and Cost less of a Long-term Physical Exercise Program to Non-medicated Hypertensive Males. Advanced Studies in Medical Sciences. 2013; 1: 111-123. Ref.: https://goo.gl/80WAEp

6. Paim J, Travassos C, Almeida C, Bahia L, Macinko J. The Brazilian health system: history, advances, and challenges. Lancet. 2011; 377: 1778-1797. Ref.: https://goo.gl/5SZcBe

7. Bertoldi AD1, Kanavos P, França GV, Carraro A, Tejada CA, et al. Epidemiology, management, complications and costs associated with type 2 diabetes in Brazil: a comprehensive literature review. Global Health. 2013; 9: 62. Ref.: https://goo.gl/wCbbwU

8. Brasil. Ministério da Saúde. Secretaria de Vigilância em Saúde. Departamento de Análise de Situação de Saúde. Plano de ações estratégicas para o enfrentamento das doenças crônicas não transmissíveis (DCNT) no Brasil 2011-2022 / Ministério da Saúde. Secretaria de Vigilância em Saúde. Departamento de Análise de Situação de Saúde. Brasília: Ministério da Saúde. 2011.

9. Moreira GC, Cipullo JP, Martin JF, Ciorlia LA, Godoy MR, et al. Evaluation of the awareness, control and cost-effectiveness of hypertension treatment in a Brazilian city: populational study. J Hypertens. 2009; 27: 1900-1907. Ref.: https://goo.gl/1gRtyO

10. Dib MW, Riera R, Ferraz MB. Estimated annual cost of arterial hypertension treatment in Brazil. Rev Panam Salud Publica. 2010; 27: 125-131. Ref.: https://goo.gl/y3jH5n

11. Schmidt MI, Duncan BB, Silva GA, Menezes AN, Monteiro CA, et al. Chronic non-communicable diseases in Brazil: burden and current challenges. Lancet. 2011; 377: 1949-1961. Ref.: https://goo.gl/MsPCDg

12. Kearney PM, Whelton M, Reynolds K, Muntner P, Whelton PK, et al. Global burden of hypertension: analysis of worldwide data. Lancet. 2005; 365: 217-223. Ref.: https://goo.gl/yn9A9N

13. Lawrence J, Appel Michael W, Brands Stephen R. Sacks -Dietary Approaches to Prevent and Treat Hypertension: A Scientific Statement From the American Heart Association. Hypertension. 2006; 47: 296-308. Ref.: https://goo.gl/4c9dbx

14. Burini RC, Kano HT, Nakagaki MS, das Neves Mendes Nunes C, Burini FHP. The lifestyle modification effectiveness in reducing Hypertension in a Brazilian Community: From the epigenetic basis of Ancestral Survival to the Contemporary Lifestyle and Public Health Initiatives. Heighpubs $\mathrm{J}$ Clin Hypertens. 2017; 1: 10-31. Ref.: https://goo.gl/Xz6QfL

15. Burini RC, de Oliveira EP, Michelin E, McLellan KCP. Epidemic obesity: An Evolutionary Perspective on the Modern Obesity Crisis to a Rationale for a Treatment. In Obesity Epidemic. 2014. Ref.: https://goo.gl/dx86lQ 
16. McLellan KCP, Manda RM, Sloan LA, Burini RC. Epigenetics of Glucose Metabolism and the Basis for T2DM Interventions. 2013; 51-70. Ref.: https://goo.gl/sShhhJ

17. Young JH. Evolution of blood pressure regulation in humans. Curr Hypertens Rep. 2007; 9: 13-18. Ref.: https://goo.gl/R8g7Db

18. Zhou, MS Aimei Wang, Hong Yu. Link between insulin resistance and hypertension: What is the evidence from evolutionary biology? Diabetol Metab Syndr. 2014; 6: 12. Ref.: https://goo.gl/DJE5Hk

19. Straub RH. Evolutionary medicine and chronic inflammatory state-known and new concepts in pathophysiology. J Mol Med (Berl). 2012; 90: 523-534. Ref.: https://goo.gl/1SzE9M

20. Johnson AR, Milner JJ, Makowski L. The inflammation highway: metabolism accelerates inflammatory traffic in obesity. Immunol Rev. 2012; 249: 218-238. Ref.: https://goo.gl/vPMfUy

21. Machnik A, Neuhofer W, Jantsch J, Dahlmann A, Tammela T, et al. Macrophages regulate saltdependent volume and blood pressure by a vascular endothelial growth factor-C-dependent buffering mechanism. Nat Med. 2009; 15: 545-552. Ref.: https://goo.gl/4B0Nv1

22. Horita S, Seki G, Yamada H, Suzuki M, Koike K, et al. Insulin resistance, obesity, hypertension, and renal sodium transport. Int J Hypertens. 2011; 2011: 391762. Ref.: https://goo.gl/911/gF

23. Soeters MR, Soeters PB. The evolutionary benefit of insulin resistance. Clin Nutr. 2012; 31: 10021007. Ref.: https://goo.gl/cOjYSp

24. Weder AB. Evolution and hypertension. Hypertension. 2007; 49: 260-265. Ref.: https://goo.gl/sKLg5a

25. Di Rienzo A, Hudson RR. An evolutionary framework for common diseases: the ancestralsusceptibility model. Trends Genet. 2005; 21: 596-601. Ref.: https://goo.gl/cfnELI

26. Tsatsoulis A, Mantzaris MD, Bellou S, Andrikoula M. Insulin resistance: an adaptive mechanism becomes maladaptive in the current environment - an evolutionary perspective. Metabolism. 2013; 62: 622-633. Ref.: https://goo.gl/nnhceD

27. Rahal A, Kumar A, Singh V, Yadav B, Tiwari R, et al. Oxidative Stress, Prooxidants, and Antioxidants: The Interplay. BioMed Research International. 2014; 2014: 761264. Ref.: https://goo.gl/R9AQBe

28. Dimitrios NT, Geogrios KC, Dmitrios IXH. Neurohormonal hypothesis in heart failure. Hellenic Journal of Cardiology. 2003; 44: 195-205. Ref.: https://goo.gl/SKcxF6

29. McEwen, Bruce S. Protective and Damaging Effects of Stress Mediators. N Engl J Med. 1998; 338: 171-179. Ref.: https://goo.gl/ut9vL

30. McEwen BS, Wingfield JC. The concept of allostasis in biology and biomedicine. Horm Behav. 2003; 43: 2-15. Ref.: https://goo.gl/EgpEoj

31. Sterling P. Principles of allostasis: optimal design, predictive regulation, pathophysiology and rational therapeutics. IN: Allostasis, Homeostasis, and the Costs of Adaptation, J. Schulkin (ed) Cambridge University Press. 2004.

32. Lücher C, Frerking M. Restless AMPA receptors: implications for synaptic transmission and plasticity. Trends Neurosci. 2003; 24: 665-670. Ref.: https://goo.gl/38F6CC

33. Ikeda H, Heinke B, Ruscheweyh R, Sandkühler J. Synaptic plasticity in spinal lamina I projection neurons that mediate hyperalgesia. Science. 2003; 299: 1237-1240. Ref.: https://goo.gl/oRVSr1

34. Eyer J, Sterling P. Stress-related mortality and social organization. Review of Radical Political Economics. 1977; 9: 1-44. Ref.: https://goo.gl/v3bDkW

35. Henry JP, Meehan JP, Stevens PM. The use of psychosocial stimuli to induce prolonged systolic hypertension in mice. Psychosomatic Medicine. 1967; 29: 408. Ref.: https://goo.gl/zSf3Mx

36. Carretero OA, Oparil S. Essential Hypertension part II: treatment. Circulation. 2000; 101: 446- 453. Ref.: https://goo.gl/tFZ4hL

37. Sacks FM, Svetkey LP, Vollmer WM, Appel LJ, Bray GA, et al. Effects of blood pressure of reduced dietary sodium and the dietary approaches to stop hypertension (DASH) diet. New Eng J Med. 2001 344: 3-9. Ref.: https://goo.gl/tWEkhM

38. Moreto F, Kano HT, Torezan GA, Oliveira EP, Manda RM, et al. Changes in malondialdehyde and C-reactive protein concentrations after lifestyle modification are related to different metabolic syndrome-associated pathophysiological processes, Diabetes and Metabolic Syndrome. 2015; 9: 218-222. Ref.: https://goo.gl/ZWMwUS 
39. Craig CL, Marshall AL, Sjostrom M, Bauman AE, Booth ML, et al. International physical activity questionnaire: 12-country reliability and validity. Med Sci Sports Exerc. 2003; 35: 1381-1395. Ref.: https://goo.gl/Za6wJL

40. Heyward VH. Avaliação da composição corporal aplicada (1 ${ }^{\text {st }}$ Edn.) São Paulo. 2000.

41. World Health Organization. OBESITY Preventing and managing the global epidemic: report of a WHO Consultation on Obesity. Geneva: World Health Organization. 1998.

42. Janssen I, Heymsfield SB, Baumgartner RN, Ross R. Estimation of skeletal muscle mass by bioelectrical impedance analysis. J Appl Physiol. 2000; 89: 465-471. Ref.: https://goo.gl/6nTxxh

43. Baumgartner RN, Koehler KM, Gallagher D, Romero L, Heymsfield SB, et al. Epidemiology of sarcopenia among the elderly in New Mexico. Am J Epidemiol. 1998; 147: 755-763. Ref.: https://goo.gl/eHzhfy

44. Janssen I, Baumgartner RN, Ross R, Rosenberg IH, Roubenoff R. Skeletal muscle cutpoints associated with elevated physical disability risk in older men and women. Am J Epidemiol. 2004; 159: 413-421. Ref.: https://goo.gl/BCvDn6

45. Bray G. An approach to the classification and evaluation of obesity. In: Bjorntorp P, Brodoff BN. Obesity. 1992; 294-308.

46. American College of Sports Medicine. ACSM's Guidelines for Exercise Testing and Prescription. 9th ed. 2013.

47. Balke B, Ware RW. An experimental study of Air Force personel. US Armed Forces Med J 1959; 10: 675-88. Ref.: https://goo.gl/64mUir

48. Nakagaki MS, Michelin E, Teixeira O, Burini RC. Cardiorespiratory Fitness and Insulin Sensitivity Response to high-Intensity Interval Training in Overweight Post- menopausal Women. Diabetes Obes Int J. 2017; 2: 000152.

49. Picon RV, Fuchs FD, Moreira LB, Riegel G, Fuchs SC. Trends in Prevalence of Hypertension in Brazil: A Systematic Review with Meta-Analysis. PLoS ONE. 2012; 7: e48255. Ref.: https://goo.gl/floZKM

50. Booth, FW, Gordon SE, Carlson CJ, Hamilton MT. Waging war on modern chronic diseases: primary prevention through exercise biology. J Appl Physiol (1985). 2000; 88: 774-787. Ref.: https://goo.gl/FYdzga

51. Posch K, Schmidt K, Graier WF. Selective stimulation of L-arginine uptake contributes to shear stress-induced formation of nitric oxide. Life Sci. 1999; 64: 663-670. Ref.: https://goo.gl/0ZWmlL

52. Corson MA, James NL, Latta SE, Nerem RM, Berk BC, et al. Phosphorylation of endothelial nitric oxide synthase in response to fluid shear stress. Circ Res. 1996; 79: 984-991. Ref.: https://goo.gl/HCfkMe

53. Ainsworth BE, Haskell WL, Whitt MC, Irwin ML, Swartz AM, et al. Compendium of physical activities: an update of activity codes and MET intensities. Med Sci Sports Exerc. 2000; 32: 498-504. Ref.: https://goo.gl/Jzi8XZ

54. Burini RC, Torezan GA, Sloan LA, Corrente JE, McLellan KCP. Dietary Intake Association with IFG and Responses of a Lifestyle Changing Protocol in a Community-B based Adult Cohort. Endocrinol Metab Synd. 2014; 3: 125. Ref.: https://goo.gl/QZHZVY

55. de Lemos AS WM, Long CJ, Sivapackianathan R, Rader DJ. Identification of genetic variants in endothelial lipase in persons with elevated high-density lipoprotein cholesterol. Circulation. 2002; 106: 1321-1326. Ref.: https://goo.gl/Tc6ofm

56. I Diretriz Brasileira de Diagnóstico e Tratamento da Síndrome Metabólica. Arq Bras Cardiol. 2005; 84: 1-28. Ref.: https://goo.gl/rd2wbu

57. Lewington S, Clarke R, Qizilbash N, Peto R, Collins R. Age-specific relevance of usual blood pressure to vascular mortality: a meta-analysis of individual data for one million adults in 61 prospective studies. Lancet. 2002; 360: 1903-1913. Ref.: https://goo.gl/Nm32SP

58. Mancia G, De Backer G, Dominiczak A, Cifkova R, Fagard R, et al. 2007 Guidelines for the Management of Arterial Hypertension: The Task Force for the Management of Arterial Hypertension of the European Society of Hypertension (ESH) and of the European Society of Cardiology (ESC). J Hypertens. 2007; 25: 1105-1187. Ref.: https://goo.gl/KOcH1K

59. McLellan et al. In: Zimering MB, Topics in the prevention, treatment and complications of Type 2 Diabetes (1st Edn), Intech Open Access Publisher. 2011. 
60. Sociedade Brasileira de Cardiologia. VI Diretrizes Brasileiras de Hipertensão. Arq Bras Cardiol. 2010; 95: 1-51. Ref.: https://goo.gl/TFyceC

61. Third Report of the National Cholesterol Education Program. (N. C. E. P.) Expert Panel on Detection, Evaluation, and Treatment of High Blood Cholesterol in Adults (Adult Treatment Panel III) final report. Circulation. 2002; 106: 3143-3421.

62. Wilson FH, Disse-Nicodème S, Choate KA, Ishikawa K, Nelson-Williams $\mathrm{C}$, et al. Human hypertension caused by mutations in WNK kinases. Science. 2001; 293: 1107-1112. Ref.: https://goo.gl/dHVZSe 